\title{
SOBRE LA NOCIÓN DE ESCRITURA EN LAS ENSEÑANZAS DE LACAN
}

\author{
On the notion of writing in Lacan's teachings
}

\author{
Karina Savio ${ }^{1}$
}

\begin{abstract}
RESUMEN
En este artículo se propone un recorrido por la noción de escritura en las enseñanzas de Jacques Lacan con el fin de identificar el sentido o los sentidos que se alojan en ella. Asimismo, se pretende analizar con qué elementos teóricos se articula, y rescatar su aporte para los estudios del lenguaje. Entre los conceptos que provienen del campo de los estudios del lenguaje, esta noción no ha sido objeto, hasta el momento, de un estudio detallado. Sin embargo, este término persiste a lo largo de los escritos y los seminarios del psicoanalista. Como resultado de este trabajo se ha podido identificar cierta continuidad, pero también ruptura, en los modos en que Lacan concibe la escritura. Mientras que en una primera instancia la escritura es definida como una marca distintiva, lo que le supone un parentesco con el significante, en un segundo momento es entendida como sostén de goce. Podría pensarse que este segundo sentido conlleva la idea de marca; sin embargo, es una marca que ha perdido su valor "distintivo", que no está ya en línea con el significante, sino que está definida desde el registro real.
\end{abstract}

Palabras clave: Estudios del lenguaje, psicoanálisis, real, escuela francesa, significante.

\begin{abstract}
The purpose of this article is to make a journey through the notion of writing in the teachings of Jacques Lacan in order to identify the sense or the senses that can be localized in it. Likewise, it pretends to analyze the theoretical elements with which it is articulated and rescue its contribution to the language studies. Among the concepts that come from the field of language studies, this notion has not been the object, until now, of a detailed study. However, this term persists throughout the writings and seminars of the psychoanalyst. As a result of this work, a certain continuity was identified, but also a break in the ways in which Lacan conceives this term. While in the first instance writing is defined as a distinctive mark, which implies a proximity with the signifier, in a second moment it is understood as support of jouissance. It could be thought that this second sense entails the idea of mark; however, it is a mark that has lost its "distinctive" value, which is no longer in line with the signifier, but is defined form the real register.
\end{abstract}

Key Words: Language studies, psychoanalysis, real, French school, signifier.

\footnotetext{
${ }^{1}$ Universidad de Buenos Aires. Doctora. Departamento de Lingüística. Argentina. Correo electrónico: karinasavio @ fibertel.com.ar Recepción: 18/05/2018. Aceptación: 09/06/2018.
} 


\section{Introducción}

La escritura es una problemática que ha abierto numerosos interrogantes, los cuales han sido planteados, analizados y debatidos por y desde diferentes dominios del saber. Lingüistas, filósofos, antropólogos, sociólogos, filólogos, historiadores, paleógrafos, educadores, entre otros, han reflexionado, y continúan haciéndolo, acerca de las diversas dimensiones que atraviesan y constituyen la complejidad de este asunto. Los orígenes, la evolución, los diversos sistemas de escritura, las funciones en la sociedad, la enseñanza-aprendizaje, los vínculos con la oralidad, las representaciones sociales, los efectos en el sujeto, el grafismo y las relaciones con el espacio son algunas de las líneas de trabajo que se han abierto y que han sido abordadas desde múltiples miradas, las cuales buscan aprehender algunos de los fragmentos de este huidizo objeto. En este horizonte, el psicoanálisis no ha permanecido ajeno a tal cuestión.

$\mathrm{Al}$ acudir al diccionario, se encuentra que en el término escritura confluyen varios sentidos, entre ellos: acción y efecto de escribir, sistema de signos y obra escrita. En el psicoanálisis, la pregunta por la función de lo escrito, en particular, el lugar de la escritura tanto en la enseñanza teórica como en la transmisión clínica, es una pregunta que ha sustentado una gran cantidad de trabajos de investigación. En efecto, el problema de la escritura interpela al psicoanálisis ya desde su nacimiento, cuestión que hoy en día sigue vigente. En estos textos se pone el foco, por ejemplo, en el modo de construcción de algunos historiales clínicos o de casos publicados, en el vínculo entre el caso clínico y la literatura, en la escritura en la formación analítica e, incluso, se analiza la escritura de Freud o de Lacan (Assoun, 1994; Baños Orellana, 1995; Beliveau, 2005; Brooks, 1992; De Certeau, 2007; Escars, 2003; Fages, 2001; Kuri, 1997; Paladino, 2003; Porge, 2007). No obstante, a diferencia de esta prolífica producción y a pesar de que Lacan se refiere a ella a lo largo de toda su enseñanza, los estudios que se han dedicado a pensar acerca del modo en que este psicoanalista entiende la escritura no han sido tan abultados como aquellos que han abordado otras nociones pertenecientes a la lingüística.

Podría señalarse, en un principio, que el término escritura no es nodular dentro de la teoría de Lacan. En efecto, entre los conceptos que provienen del campo de los estudios del lenguaje y que son incorporados y moldeados en el marco del psicoanálisis lacaniano, este término no ha merecido - dentro de la bibliografía psicoanalítica- una lectura minuciosa. Si bien se remite a la problemática de la escritura en Lacan, en especial, a las referencias lacanianas sobre la escritura china, en una gran cantidad de ensayos y artículos 
psicoanalíticos, pocos han sido los autores que han revisado con mayor detenimiento el devenir de esta noción (véase Fasolino, 2012; Frucella, 2015; Fuentes, 2010; López, 2009). Esta exigua producción contrasta con la insistencia -que abarca desde sus trabajos más tempranos y que persiste en sus últimas clases- del significante escritura a lo largo de todos los escritos y los seminarios del psicoanalista francés. Un recorrido por los lugares en los que este aparece nos revela, a su vez, que los trabajos respecto del origen de la escritura, fundamentalmente el de Février (1948) y el de Gelb (1985), le sirven de apoyo para dar forma a ciertas reflexiones teóricas. En el presente artículo se propone revisar, entonces, el sentido o los sentidos que adopta la noción escritura en el pensamiento lacaniano, analizar los elementos teóricos con los que se la asocia y, finalmente, rescatar su novedoso aporte.

El psicoanálisis lacaniano ha incidido, sin lugar a duda, en el campo de los estudios del lenguaje, especialmente en el advenimiento de la perspectiva francesa del análisis del discurso. La preeminencia del lenguaje en su articulación con el sujeto, el inconsciente y el Otro ha permitido, entre otros puntos, cuestionar y disentir con la idea de un hablante dueño de su decir, lo que ha modificado la manera de abordar las prácticas discursivas. Por esta razón, se entiende que la revisión del modo o de los modos en que Lacan utiliza términos específicos, tales como significante, discurso, sujeto de la enunciación, letra y lengua, permite problematizar ciertas concepciones que se presentan, muchas veces, cristalizadas en el saber lingüístico. ${ }^{2}$ El presente caso, en el que se rastrea el término escritura, conducirá, además, a retomar los últimos desarrollos lacanianos que no suelen ser incorporados dentro de los estudios sobre el lenguaje, en los que se impone la pregunta por lo real y su relación con el lenguaje.

Para este recorrido se han identificado aquellos lugares en los que se advierte la noción de escritura y se ha realizado una lectura, nuestra lectura, sobre aquellos elementos que dan cuenta de una posible definición. Es necesario aclarar, antes de comenzar este camino, que la escritura aparece enlazada con distintas preocupaciones e intereses de Lacan que, en algunos casos, escapan al interés del presente trabajo. Por este motivo, no se adentrará en ciertas polémicas - como la que se establece con Derrida- o en planteos teóricos que se alejan del objetivo propuesto.

\footnotetext{
${ }^{2}$ Con este objetivo, se analizaron las nociones de discurso y de sujeto de la enunciación en artículos anteriores (Savio, 2015; 2017).
} 
A partir de este análisis se ha ubicado que el término escritura adquiere, en líneas generales, dos sentidos: mientras que en los primeros seminarios de Lacan la escritura es entendida en tanto marca distintiva, en un segundo momento, a partir del Seminario XVIII, es considerada sostén de goce. Estos sentidos no son, por otra parte, excluyentes o antagónicos. En efecto, definir la escritura como sostén de goce conlleva la idea misma de inscripción. En los siguientes apartados se expondrán con mayor detalle estas dos vertientes. Para ello, como paso previo, será necesario acercarse a algunas de las problemáticas con las que se asocia frecuentemente la escritura.

\section{Un acercamiento al problema de la escritura desde afuera del psicoanálisis}

Como ya se ha señalado en la introducción, los trabajos que abordan la escritura son numerosos y diversos, en tanto analizan -desde diferentes enfoques- distintas aristas de este objeto. En este apartado se propone dejar delineados, sin ánimo de exhaustividad, solamente algunos de los planteos teóricos que se han desarrollado en torno a la escritura, los cuales se consideraron centrales a la hora de entender su dinámica. Por esta razón, con la finalidad de aproximarse a esta materia tan compleja, se ubicará tal práctica en su articulación con cuatro dimensiones: la oralidad, la tecnología, la memoria y el poder.

En primer lugar, es importante subrayar que la historia de la escritura indica que esta no surge ni como complemento ni como suplemento de la lengua oral. Tampoco aparece en relación de subordinación o de dependencia. En efecto, los primeros indicios encontrados no revelan que hayan sido utilizados como un medio de transcripción de la oralidad. Este es el caso de la primera escritura pictográfica de la que aún quedan vestigios, cuyo nacimiento se remonta al 3.300 a. C. aproximadamente. El vínculo entre los primeros pictogramas sumerios y la lengua, afirma Calvet (2008), es contingente. Los signos empleados no conllevan rastros de su pronunciación, es decir, estos grafismos no son usados con el fin de obtener una transcripción precisa del habla. Son una "escritura de las cosas" (Calvet, 2008, p. 53), ${ }^{3}$ sin vinculación directa con la lengua oral. Este sistema se complejizará después con la escritura cuneiforme. Esto nos conduce a pensar que ya desde el alumbramiento de la escritura esta se conformará, entonces, como un código diferenciado del código oral, por lo que presentará rasgos y características singulares, propias de su devenir.

\footnotetext{
${ }^{3}$ La cursiva es del original.
} 
La escritura, en segundo lugar, ha sido definida en tanto tecnología. En este sentido, Williams (1992) entiende la tecnología, por un lado, como el marco de conocimientos necesarios para el desarrollo de habilidades y aplicaciones y, por el otro, como un marco de conocimientos y condiciones para el uso y la aplicación prácticas de una serie de ingenios. Es, a su vez, siempre social. La escritura, siguiendo este autor, es una tecnología de la comunicación de tipo instrumental, lo que implica una forma de relación social. Esta comunicación implica un otro, el lector. La escritura involucra, además, instrumentos y materiales de escritura, pero también un conocimiento específico y la habilidad para leer. Ong (2006), en este sentido, también se refiere a la escritura como tecnología de la palabra. Él subraya su carácter artificial y externo, y el aprendizaje que se requiere para su práctica, pero también marca su rol en la transformación de la conciencia humana, específicamente, en los procesos del pensar. Respecto del lector, sostiene que su relación con el escritor es bidireccional: el escritor necesita crear un papel que pueda ser desempeñado por los lectores ausentes y el lector, por su parte, crea en su lectura al escritor.

Otro punto que ha sido ampliamente debatido es la relación entre la escritura y la memoria. Recordemos que esta es una polémica que se remonta a la antigüedad; Platón (2007, p. 200) alude a ella cuando en Fedro acusa a la escritura de favorecer el olvido (“Pues este invento producirá olvido en las almas de los que aprendieron", dirá Sócrates a través del rey Thamus). Una de las particularidades más significativas de esta tecnología es que, a diferencia de la fugacidad de la lengua oral, ella conserva la palabra. En efecto, Calvet (2008, p. 46) señala que el principio rector de cualquier escritura es "que lo que se desea relatar y comunicar quede salvaguardado, que permanezca". Ong (2006, p. 81), en cuanto a este carácter fijo, manifiesta que un texto no puede ser refutado directamente: "[d]espués de una impugnación generalizada y devastadora, dice exactamente lo mismo que antes". Esta condición implica, además, que el texto escrito esté separado de su contexto directo de producción -"[L]as palabras se encuentran solas en un texto", recuerda Ong (2006, p. 102)- y que pase del sonido al espacio visual. Este espacio visual y, posteriormente, la impresión, le otorgan a la lengua nuevas dimensiones que irán modificando la relación entre la lectura y la escritura.

Por último, hay que detenerse brevemente en el vínculo entre la escritura y el poder. En la historia sobre el origen de esta práctica se suele destacar que su nacimiento está determinado por dos factores: el factor urbano y las necesidades administrativas. 
Según Calvet (2008), las inscripciones de los primeros recipientes sumerios encontrados aluden a una suerte de garantía de contrato en el que se consignaba la cantidad de corderos que debían ser entregados. De esta forma, los primeros usos de la escritura se corresponden con la contabilidad, pero también con la legislación, los ritos funerarios, la magia y adivinación, y la religión. Es más tarde que la escritura pasa a ocuparse de conservar la memoria social "tanto en lo que se refiere a su aspecto estético (epopeyas, poesía, etc.) como a su aspecto tecnológico (transmisión de saberes, de técnicas, etc.)" (Calvet, 2008, p. 279). No obstante, a pesar de que las funciones se amplíen, la restricción al acceso al conocimiento de la escritura a lo largo del tiempo seguirá actuando como un factor de poder, ya que permanecerá exclusivo de un pequeño grupo cerrado que conservará así su prestigio.

\section{La escritura desde Lacan}

\subsection{La escritura como marca distintiva}

En el psicoanálisis, la referencia a la escritura para dar cuenta de ciertos nudos teóricos se puede ubicar tempranamente en algunos textos freudianos. ${ }^{4}$ En efecto, Freud alude a ella -a su proceso y también a distintos tipos de escrituras- al concebir tanto el aparato psíquico como también su teoría del sueño. ${ }^{5}$ En este artículo se observará que Lacan, por su lado, parte de la lingüística, la lógica y la topología para remitir a la escritura a lo largo de sus enseñanzas.

En un primer momento, en el Seminario IX. La identificación (s. f. a), en el Seminario XIII. El objeto del psicoanálisis (s. f. b) y en el Seminario XIV. La lógica del fantasma (s. f. c) la escritura es entendida en tanto huella, en tanto inscripción. En este sentido, Lacan articula la constitución del sujeto con la escritura, en particular, con la escritura primitiva, con una escritura que no es fonética y que vale en tanto marca distintiva. Es interesante recuperar en este punto la etimología de la palabra escritura. Calvet (2008) recuerda que el latín scribere remite a "trazar caracteres" y que, según su

\footnotetext{
${ }^{4}$ En "Freud y la escena de la escritura" Derrida (1989) desarrolla esta articulación, y plantea, a la luz de la lectura de algunos escritos freudianos, que el contenido de lo psíquico es representado por un texto de esencia gráfica y que el sueño está conformado por una escritura irreductible al habla; una escritura "primaria" que no se lee a partir de ningún código. No nos adentraremos aquí -por alejarse de nuestros objetivos- en la polémica entre Lacan y Derrida sobre esta cuestión. Para ampliar sobre el tema se puede consultar la tesis de Frucella (2015).

${ }^{5}$ No nos detendremos sobre este punto para no desviarnos de la problemática que trabajamos aquí. Véase, por ejemplo, Freud (1992).
} 
etimología, la escritura era una especie de incisión, de corte. Por este motivo, al principio, la actividad de escribir era equivalente "a realizar incisiones, a arañar, lo que hace suponer que las piedras o vasijas fueron sus primeros soportes" (Calvet, 2008, p. 31). ${ }^{6}$

Antes de desplegar estos primeros esbozos, es necesario retomar dos de los textos con los que Lacan dialoga en este momento, a los que ya se han hecho referencia en la introducción de este artículo: Histoire de l'ecriture de James Février (1948) e Historia de la escritura de Ignace Gelb (1985), publicado en 1952 bajo el título A study of writing. Entre ambos, es el primero el que es más citado en las enseñanzas de Lacan. Allí Février se remonta al nacimiento de la escritura y realiza un recorrido por los diferentes tipos de escrituras: las escrituras mnemotécnicas y sintéticas, las escrituras americanas, las escrituras ideográficas, las escrituras semíticas, los alfabetos griego, etrusco y latín, entre otros temas. Asimismo, define la escritura como un procedimiento que sirve para inmovilizar o fijar la lengua articulada, fugitiva por su esencia misma, y plantea que es un medio de expresión permanente que nace a partir de una combinación de medios de expresión.

Por su parte, Gelb (1985) también se remite a la evolución de la escritura. Hace referencia, entonces, a los precedentes de esta práctica, a los sistemas logo-silábicos, a las escrituras silábicas y al alfabeto, pero también se refiere a cuestiones relativas a la escritura y a la civilización. A diferencia de Février, su objetivo es más ambicioso: sentar las bases para la creación de la ciencia de la escritura. Incluso propone nombrarla como "gramatología". En estas páginas, el historiador define la escritura como un sistema de intercomunicación humana por medio de signos convencionales visibles. Discute con el presupuesto de que existe cierta equivalencia entre la lengua escrita y el habla. Ni en el comienzo el mensaje escrito se correspondía a formas exactas de la lengua, ni tampoco en la escritura fonética existe una equivalencia absoluta entre ambos. A su vez, afirma que la aparición de la escritura está acompañada de un notable desarrollo del gobierno, las artes, el comercio, la industria, el transporte, la agricultura y la domesticación de los animales: "La escritura existe solamente en una civilización y una civilización no puede existir sin escritura" (Gelb, 1985, p. 286). ${ }^{7}$

Ahora bien, siguiendo a Lacan, en la clase seis del 20 de diciembre de 1961 del Seminario IX. La identificación (s.f.a) el psicoanalista recupera la historia sobre el origen

\footnotetext{
${ }^{6}$ La cursiva es del original.

${ }^{7}$ La cursiva es del original.
} 
de la escritura para dar cuenta de la función del nombre propio. En este encuentro menciona y recomienda la lectura del libro Histoire de l'écriture y recuerda la existencia de antiguas escrituras -como la escritura cuneiforme- en la que no existe una correspondencia fonética entre el signo escrito y aquello que designa. En este marco, se ocupa de la aparición del ideograma -que se convertirá luego en la base de la escritura silábica-, cuya característica es la pérdida o el borramiento del carácter de la imagen a la que, en un principio, esta reenvía. Lo que resta en estos ideogramas, señala el psicoanalista, es algo del orden del trazo unario que funciona como marca distintiva. En este sentido, los significantes de esta primera escritura son producidos en tanto marcas, que, a su vez, están asociadas con el trazo (o rasgo) unario. Recordemos que el rasgo unario es entendido a la altura de este seminario como el soporte de la identificación que hace surgir al sujeto, como la primera relación del sujeto con el significante. ${ }^{8}$

Este parentesco que se establece entre la escritura y la constitución del sujeto desemboca al final de la clase en una reflexión sobre el nombre propio. Según el psicoanalista, el nombre propio está más ligado a la escritura que al sonido: "Lo que distingue a un nombre propio a pesar de las pequeñas apariencias de comodatos (...) es que de una lengua a otra eso se conserva en su estructura" (Lacan, s. f. a., pp. 24-25). Por tal razón, el nombre propio tiene afinidad con la marca distintiva de la escritura, es decir, con la unión directa del significante con cierto objeto; no puede ser, por ello, traducido. Es interesante observar, entonces, que, mientras que Février (1948) pone el acento en el rasgo fijo e inmóvil de la escritura y Gelb (1985) en la idea de sistema, en este seminario se rescata su carácter de marca distintiva.

En la clase nueve, la noción de escritura y la escritura china son mencionadas para dar cuenta nuevamente del sujeto. En este encuentro, Lacan explica la constitución del sujeto a partir del nacimiento del significante. En este sentido, en primer lugar, sostiene que un significante es una marca, una huella, una escritura, pero que no puede leerse solo. La escritura aparece homologada nuevamente con la marca y, además, es enlazada con el significante. Como veremos en el apartado siguiente, esta relación sufrirá, luego, un giro clave en los trabajos lacanianos. En efecto, en contraposición con esta primera etapa, en los años posteriores Lacan se esforzará por hacer una distinción entre escritura y significante. En segundo lugar, para ilustrar la articulación significante, el psicoanalista

\footnotetext{
${ }^{8}$ Para una ampliación sobre el rasgo unario en el Seminario IX. La identificación (s. f. a) véase Haddad (2014).
} 
toma el caso de la escritura china. En consonancia con la definición del significante, en la que este representa un sujeto para otro significante, ubica, a partir de un ejemplo, cómo los caracteres chinos cobran sentido en función del contexto. En efecto, estos caracteres pueden combinarse según ideas y sentidos, pero también a partir de sonidos.

En la clase once, dictada el 28 de febrero de 1962, Lacan insiste en la referencia a la escritura en su relación con la función del trazo unario, en tanto este hace aparecer la génesis de la diferencia:

(...) es decir en la repetición de lo aparentemente idéntico, que se crea, se desprende lo que yo llamo, no el símbolo, sino la entrada en lo real como significante inscripto - y eso es lo que quiere decir el término de primacía de la escritura - la entrada en lo real - es la forma de ese trazo repetido por el cazador primitivo - de la diferencia absoluta en tanto que ella está ahí(Lacan, s. f. a., p. 19). $9^{9}$

En esta cita observamos que se establece, por primera vez, una articulación entre la escritura y lo real, ${ }^{10}$ que será retomada y trabajada con mayor profundidad en los años siguientes. ${ }^{11}$ La escritura primitiva -entendida como marca, como inscripción- es la que habilita que algo de la diferencia aparezca. La escritura de esta marca, de esta marca primera, en la constitución del sujeto, implica la entrada en lo real.

La cuestión de la escritura es retomada unos años después en el Seminario XIII. El objeto del psicoanálisis, que se dicta entre los años 1965 y 1966. En este seminario, puntualmente, en la tercera clase del 15 de diciembre de 1965, Lacan (s. f. b) asocia nuevamente la definición del significante, por su carácter articulado, con la escritura china. Pero además -y aquí radica la novedad- discute con la concepción de la escritura que entiende la escritura como un simple instrumento del lenguaje. En efecto, la escritura no es un mero instrumento, una mera herramienta del lenguaje, que reflejaría así las

\footnotetext{
${ }^{9}$ La cursiva es del original.

${ }^{10}$ Es complejo definir brevemente algunos de los términos lacanianos que atraviesan toda su enseñanza y que sufren, por ello, modificaciones en el modo en que se los concibe. No obstante, es importante aclarar que Lacan plantea la existencia de tres registros -real, simbólico e imaginario- sobre los que apoya su teorización. Estos irán teniendo distinto valor y significado en su discurso. De manera simplificada, y por tanto, inexacta, podríamos señalar que el registro de lo imaginario está en relación con la imagen y que es conceptualizado, fundamentalmente, al dar cuenta del estadio del espejo. En cambio, lo simbólico está vinculado, principalmente, con el significante y la falta. Por último, lo real, cuya definición irá cambiando a lo largo del tiempo, es aquello que escapa a la simbolización y al imaginario; es definido en los últimos años como lo imposible y está puesto en relación con el goce y el síntoma.

${ }^{11}$ Véase apartado siguiente.
} 
palabras. No es una simple copia de la realidad, sino que, por el contrario, posee una función estructural. En la misma línea que en el Seminario IX. La identificación esta función estructural es equiparada con la prevalencia dada a la función del rasgo unario a nivel de la identificación. Es decir, la identificación al rasgo unario cumple una función estructural en la constitución subjetiva, al igual que la escritura la cumple respecto al lenguaje. En este sentido, recuerda que los signos del alfabeto no nacen de la necesidad de codificar los fonemas, sino que provienen de signos anteriores. En este seminario Lacan sigue pensando, entonces, la escritura como una marca. De allí que en la clase del 5 de enero de 1966 aluda a la escritura original, aquella que existe antes de servir como escritura de la palabra, como una huella, un surco, un corte.

Finalmente, en el seminario siguiente, el Seminario XIV. La lógica del fantasma (s. f. c), dictado entre 1966 y 1967, retorna a la cuestión de la escritura. En estas clases despliega la fórmula del fantasma $(\$ \diamond a)$, fórmula que remite a la relación entre el sujeto dividido y el objeto $a$, objeto causa del deseo. El fantasma es aquello que le permite al sujeto sostener su deseo y en el grafo del deseo surge como respuesta al deseo enigmático del Otro. En las primeras páginas de este seminario, en la primera clase, al retomar una vez más la constitución del sujeto y su relación con la articulación significante, recuerda que durante dieciséis siglos aproximadamente los jeroglíficos egipcios permanecieron incomprendidos:

Está claro, y siempre estuvo claro para todo el mundo, que esto quería decir que cada uno de los significantes grabados en la piedra, como mínimo, representaba un sujeto para los otros significantes. ¡Si no hubiera sido así, nunca nadie habría tomado a eso por una escritura! De ninguna manera es necesario que una escritura quiera decir algo para quien sea, para que ella sea una escritura, y para que, como tal, manifieste que cada signo representa un sujeto para el que le sigue (Lacan, s. f. c., p. 21).

El valor de la escritura no está, entonces, en lo que quiere decir, en el "mensaje", sino en la articulación significante. La marca, por ello, está primero; es anterior al sentido que se le otorga. Lo mismo vale, afirma el psicoanalista, para la represión originaria, aquella que divide al sujeto.

En la reunión siguiente, del 23 de noviembre de 1966, Lacan considera, en primera instancia, que el fantasma está en relación con una escritura, y manifiesta que hay una relación estrecha entre el aparato de la escritura y la lógica. Luego, a partir de ejemplos 
tomados de la lógica, ilustra la cuestión de la repetición y postula que esta busca repetir aquello que se le escapa, por la función misma de la marca. Repetir la marca original queda fuera del alcance; ninguna repetición, por su naturaleza, puede repetir esa primera marca. De esta manera, el estatuto de la función de la escritura está constituido por la función de la falta: "La escritura de la que hablo no se soporta más que del retorno" (Lacan, s. f. c., p. 19). Aquí ya se vislumbra aquello que Lacan madurará unos años después: el vínculo entre la escritura y el goce, eje sobre el que nos adentraremos en el apartado siguiente.

\subsection{La escritura como sostén de goce}

En 1971, en el Seminario XVIII. De un discurso que no fuera del semblante (2014) se produce una modificación medular respecto al modo en que Lacan entiende la escritura. Desde este seminario, la escritura es concebida como una marca, una inscripción, pero también es entendida como sostén de goce. Asimismo, a partir de aquí la escritura va a estar claramente diferenciada del significante: mientras que la escritura quedará ubicada dentro del orden de lo real, el significante estará relacionado con el registro de lo simbólico. En este segundo momento, Lacan se pregunta, además, por los vínculos entre escritura y práctica analítica.

Asimismo, en el Seminario XVIII. De un discurso que no fuera del semblante, en el que se plantea un discurso más allá de lo imaginario, más allá de lo simbólico, el psicoanalista francés vuelve a hacer uso de la escritura china con el objetivo de reflexionar, entre otras cuestiones, en torno a la función de la escritura y a la ambigüedad de lo escrito. ${ }^{12}$ En la clase del 10 de marzo, en la que sostiene que no hay topología sin escritura, vincula a esta con los grafos, en particular con el grafo del deseo, y señala que la escritura se distingue de la palabra que puede apoyarse allí. En esta misma línea, a partir de la existencia de pictogramas/ideogramas, discute con el presupuesto de que lo que suele llamarse escritura es algo que de alguna manera se refleja en la palabra. En efecto, la escritura es entendida como la representación de palabra (Freud mismo hace mención de la representación palabra -Wortvorstellung-en algunos trabajos). ${ }^{13}$ Este

\footnotetext{
12 Tanto en este seminario como en "Lituraterre" Lacan (s. f. d) polemiza con la concepción de escritura que sostiene Derrida. Como ya hemos señalado, no desarrollamos este tema por no ser el objetivo del artículo. Se recomienda, para este tema, ver Frucella (2015).

${ }^{13}$ Saussure (2007) define la escritura como representación de la lengua.
} 
presupuesto conlleva la idea de que la palabra es previa a la escritura, ya está ahí antes de ser representada. No obstante, para Lacan, la escritura no es simple representación, ya que representación significa también repercusión: "Tal vez sea la representación como tal la que hace a las palabras" (2014, p. 84). Por esta razón, define la escritura como eso de lo que se habla: la escritura produce efectos.

Esta posición está en consonancia con el título de los Escritos de Lacan. Recordemos que muchos de los trabajos que componen estos volúmenes tienen un origen oral. De esta manera, al nombrarlos Escritos, el psicoanalista no solamente remite a los grafos que estos escritos contienen, sino también a que ellos conducen "a todo tipo de malentendidos" (2014, p. 57). Estos escritos tienen efectos, interpelan al lector para que produzca sentidos sobre lo que lee.

En la clase del 12 de mayo, en la que recuerda un viaje en avión por la planicie siberiana en la que la lluvia deja trazos o surcos, semejantes a una escritura, distingue esta última del significante: "La escritura, la letra, está en lo real, y el significante, en lo simbólico" (2014, p. 114). En esta reunión Lacan define la letra como litoral, ya que separa dos dominios heterogéneos, y la ubica en relación con el inconsciente. ${ }^{14}$ Esta articulación entre escritura y real es retomada en el encuentro siguiente, en el que el psicoanalista manifiesta que lo escrito es el goce, y en la clase del 9 de junio. En este último encuentro Lacan afirma que, desde sus orígenes hasta sus últimas variaciones técnicas, la escritura no ha sido simple inscripción. Por el contrario, es sostén de los goces que, por el discurso, parecen abrirse al ser hablante.

En este mismo año Lacan publica el artículo "Lituraterre" en el número 3 de la revista Littérature, en el que se refiere a cuestiones que desarrolla en este seminario. Aquí retoma una definición que despliega en el seminario y que asocia con el vuelo por Siberia:

Es por el mismo efecto que la escritura es en lo real la erosión del significado, lo que ha llovido del semblante en tanto que él hace el significante. Ella no calca a éste, sino sus efectos de lengua, lo que se forja de ésta por medio de quien la habla (s. f. d., p. 21).

\footnotetext{
${ }^{14}$ El modo en que Lacan conceptualiza la noción de letra a lo largo de su enseñanza y su relación con la escritura excede los límites y objetivos del trabajo. Para un acercamiento a esta problemática consultar López (2009).
} 
La escritura, en este sentido, sigue siendo pensada en tanto surco, marca, pero, dado que pertenece al registro de lo real, ya no es un "calco" del significante. Es efecto del lenguaje y no solamente su representación.

En el Seminario XX. Aún, dictado entre 1972 y 1973, Lacan (2008) vuelve sobre la función de lo escrito en la clase del 9 de enero de 1973. En este texto insiste en la diferenciación entre la escritura y el significante, pero, en contraposición con lo que despliega en años anteriores, reflexiona sobre una problemática que no ha sido abordada previamente: el vínculo entre la función de lo escrito y el discurso analítico. En este punto, plantea que en el discurso psicoanalítico no se trata sino de lo que se lee, más allá de lo que se ha incitado al sujeto a decir, esto es, lo que se lee a partir de la asociación libre del analizante. En este sentido, el significado no tiene que ver con lo oído, sino con la lectura de lo que se escucha del significante: el significado es el efecto del significante. Por ello, manifiesta que a lo que se enuncia como significante en el discurso analítico se le da una lectura diferente de lo que significa. En relación con esto, y en continuidad con lo planteado en el Seminario XVIII. De un discurso que no fuera del semblante, manifiesta que lo escrito, entonces, no está para ser comprendido: "Por esto, precisamente, nadie está obligado a comprender los míos. Si no los comprenden, tanto mejor, pues tendrán la oportunidad de explicarlos" (2008, p. 46).

En esta misma clase articula, en primer lugar, la relación sexual con la escritura, ligazón sobre la que regresa en los seminarios siguientes. La relación sexual, sostiene Lacan, no puede escribirse: "Todo lo que está escrito parte del hecho de que será siempre imposible escribir como tal la relación sexual. A eso se debe que haya cierto efecto de discurso que se llama escritura" (2008, p. 46). En otras palabras, no es posible formalizar la relación sexual, ya que esta es imposible, escapa a la escritura. En segundo lugar, con respecto a que la escritura es efecto del discurso, ilustra esta posición con el ejemplo de las letras del alfabeto fenicio. Lacan recuerda que estas letras se encontraban en cerámicas egipcias que servían como marcas de fábrica antes de ser empleadas en el alfabeto como letras. Siguiendo la postura que mantiene en el seminario anterior, afirma que el lenguaje se perfecciona cuando este sabe jugar con la escritura, por lo que recuerda la escritura de Joyce.

Por último, en la clase del 15 de mayo define la formalización matemática como escritura, afirmación que jugará un papel central en futuros seminarios. En este encuentro insiste en la idea de una escritura en tanto huella, marca en la que se lee un efecto de 
lenguaje. Podría pensarse, entonces, que la escritura -incluso, la escritura original, "primitiva"- es secundaria al lenguaje. Lo "secundario" aquí no implica que la escritura sea menos importante que el lenguaje, sino que deriva de este.

El Seminario XXI, al que Lacan sugiere como título Les non-Dupes Errent o Les Noms Du Pere, se realiza entre 1973 y 1974. Aquí se refiere al nudo borromeo, nudo conformado por tres aros enlazados de tal forma que si se desprende uno de ellos se separan los otros dos. Este nudo representa la estructura constituida por los tres registros -real, simbólico, imaginario- y su triple enlace define el objeto $a$. En este seminario, en la clase del ocho de enero de 1974, el psicoanalista reitera que no se debe confundir la letra con la palabra y manifiesta que solo la escritura hace que los tres registros se constituyan en tres. La escritura estará en función, a partir de aquí, con el nudo borromeo, por lo que los desarrollos lacanianos comenzarán a tomar distancia de la idea de la escritura como "representación palabra".

En la última reunión, la del 21 de mayo, propone el nudo borromeo como un modo de escritura ${ }^{15}$ y afirma que este nudo presentifica el registro de lo real. En este encuentro afirma que solo la escritura soporta ese real: "Es siempre por una referencia a la escritura que aquello que puede ser situado en el lenguaje encuentra su real" (s. f. e., párr. 21). La novedad de esta clase reside en que en estas páginas la escritura queda vinculada con el inconsciente: "es del lado de la escritura que se concentra aquello donde trato de interrogar acerca del inconsciente cuando digo que el inconsciente es algo en lo real" (s. f. e., párr. 9).

Esta línea de trabajo persiste en el Seminario XXII. R.S.I., desarrollado entre 1974 y 1975, ya que en estos encuentros piensa el nudo borromeo como una escritura que soporta un real. En la segunda clase, dictada el 17 de diciembre, afirma: "Ya esto, por sí solo, designa lo siguiente: es que no solamente lo Real puede soportarse de una escritura, sino que no hay otra idea sensible de lo Real" (s. f. f., p. 2).

El Seminario XXIII. El Sinthome (1975-1976) está dedicado, en gran medida, a analizar el "caso" James Joyce, a partir del cual Lacan estudia el modo en el que el arte cumple para el escritor una función de suplencia. ${ }^{16}$ Respecto del nudo borromeo, plantea aquí, entre otros puntos, la existencia de un cuarto redondel -la función de padre-, que

\footnotetext{
15 Se refiere al nudo como "esa escritura" y "ese objeto de escritura".

${ }^{16}$ Para el caso de Joyce, Lacan plantea que es la escritura aquella que cumple la función de cuarto nudo.
} 
anuda y asegura los otros tres aros. Ahora bien, en la clase del 13 de enero de 1976, en la que comienza haciendo referencia al cuerpo, menciona los libros de Février (1948) y de Gelb (1985) para pensar el vínculo entre escritura y real:

Con todo lo que consumí de historia de la escritura, incluso de teorías de la escritura - hay un llamado Février que hizo la historia de la escritura, hay otro que se llama Gelb quien hizo una teoría de la escritura - empecé a fantasear.

Me interesa porque pienso que históricamente se ha entrado en lo real por fragmentos de escritura, a saber, se cesó de imaginar. La escritura de las letritas matemáticas sostiene lo real (Lacan, 2006, p. 66).

En este extenso fragmento se observa que Lacan compara la escritura en sus orígenes con la matemática, y la asocia, una vez más, con lo real. La escritura está en relación con el nudo.

El 11 de mayo de 1976, última clase del seminario, el psicoanalista retoma la problemática de la escritura y postula la existencia de dos modos diferentes de concebirla. Por un lado, hace referencia a aquella que entiende la escritura como precipitación del significante. A pesar de que esta posición se la atribuye a Derrida, se podría pensar que no está muy alejada a la que esgrime el mismo Lacan en sus elaboraciones previas, en las que, como ya se ha destacado, hace referencia a la lluvia del significante. Por el otro, la asocia con el nudo. Afirma, entonces, a través de un juego de palabras, que el nudo es un apoyo para el pensamiento/apensamiento y, luego, define la escritura como un hacer que da soporte al pensamiento. En efecto, es a partir de la escritura que se puede transmitir el nudo; es necesario escribir el nudo para que se pueda decir algo de él, para ver cómo funciona. Escribir el nudo es la única manera de reproducirlo. De esta forma, Lacan contrasta y distingue la idea de escritura en tanto precipitación del significante con la escritura entendida como soporte. A diferencia de la postura derridiana, según Lacan, el significante, que se modula con la voz, no tiene nada que ver con la escritura. Esta distinción queda demostrada, para el psicoanalista, en el nudo borromeo, al que se le pueden "enganchar" significantes.

Es interesante observar que en este encuentro el psicoanalista recuerda sus desarrollos previos acerca de la escritura y el rasgo unario: 
La escritura en cuestión viene de otra parte que del significante. No fue sin embargo ayer cuando me interesé en este asunto de la escritura y cuando la promoví la primera vez que hablé del rasgo unario, einziger Zug en Freud.

Debido al nudo borromeo, di otro soporte a este rasgo unario. Aún no les expuse este otro soporte. En mis notas, lo escribo DI. Son las iniciales de dorite infinite [recta infinita] (Lacan, 2006, p. 143).

Pone, por ende, en continuidad la idea de escritura en tanto marca asociada al rasgo unario con la escritura como soporte del nudo.

Por último, el Seminario XXV. El momento de concluir (s. f. f) es dictado a fines de 1977 y finaliza en mayo de 1978. Aquí el psicoanalista vuelve a establecer una correspondencia entre la escritura y la práctica analítica, es decir, aquello que ocurre en la sesión. En efecto, en la tercera clase, la del 20 de diciembre, plantea que ni en lo que dice el analizante ni en lo que dice el analista hay otra cosa que escritura. El analista participa de la escritura. A través del corte zanja, escribe, escribe de otro modo sobre lo que dice el analizante sin que este sepa lo que dice cuando habla. El analista lee, entonces, ese decir que va más allá de la intención consciente de quien se encuentra en análisis.

En la siguiente reunión -la del 10 de enero- la escritura, definida como artificio, vuelve a ser entendida desde el registro real. En este encuentro Lacan afirma que lo real aparece en tanto hay escritura. En este sentido, la escritura se erige como condición de lo real y está ligada al inconsciente:

Hay seguramente escritura en el inconsciente, no sería más que porque el sueño, principio del inconsciente -eso es lo que dice Freud-, el lapsus e incluso el chiste se definen por lo legible. Un sueño, uno lo hace, no sabe por qué y luego, retroactivamente, eso se lee; un lapsus igual, y todo lo que Freud dice del chiste es bien notorio como estando ligado a esa economía que es la escritura, economía en relación a la palabra. (s. f. f., párr. 19)

De esta forma, en el inconsciente hay escritura, ya que el sueño, el chiste y el lapsus se "leen" retroactivamente. La escritura aparece unida, así, con la lectura:

Al saber sobre el inconsciente se accede, entonces, a partir de esa lectura:

Lo legible, es en eso que consiste el saber. Y en suma, es escaso. Lo que digo de la transferencia es que la he adelantado tímidamente como siendo el sujeto -un 
sujeto es siempre supuesto, no hay sujeto por supuesto, no hay más que supuestosupuesto-saber. ¿Qué es lo que eso puede querer decir? El supuesto-saber-leer-deotro-modo (Le supposé-savoir-lire- autrement). (s. f. f., párr. 20)

De esta cita se desprende que el movimiento del analista consiste en esa lectura, en leer ese saber que dice el analizante sin saberlo.

\section{Conclusiones}

Los últimos años de la enseñanza de Lacan, en los que lo real cobra un lugar medular en su producción, no suelen ser ni revisados ni problematizados en el campo de los estudios del lenguaje. Sin embargo, esta etapa permitiría abrir numerosas preguntas que interrogan algunas certezas respecto del lenguaje y de la lengua. Si retomamos aquello que Lacan plantea en el Seminario XXV. El momento de concluir, podría pensarse que el analista del discurso -al igual que el psicoanalista- interviene, también, en la escritura de un texto. Puntúa, corta, cincela y encuentra huellas y marcas que reenvía a otras escrituras. Escribe, así, sobre lo que ya está escrito, produciendo con ello nuevos sentidos.

En este artículo se ha buscado establecer un recorrido por las enseñanzas de Lacan con el fin de localizar el sentido o los sentidos que se alojan en la noción de escritura y pensar, y, a partir de allí, reconocer la novedad que el psicoanalista aporta. Este camino nos ha permitido identificar cierta continuidad, pero también ruptura en los modos en que este término es concebido. Mientras que en una primera instancia la escritura es definida como una marca distintiva, lo que le supone un parentesco con el significante, en un segundo momento es entendida como sostén de goce. Podría pensarse que este segundo sentido conlleva la idea de marca; sin embargo, es una marca que ha perdido su valor "distintivo", que no está ya en línea con el significante, sino que está definida en tanto real.

Como se ha visto en el desarrollo, el pensamiento lacaniano utiliza la figura de la escritura para reflexionar sobre el sujeto. No le interesa, por ello, su cara social y política. Esta concepción de la escritura se aleja así de aquella que la entiende como un instrumento, un medio. En tanto vale por sí misma, no forma parte del lazo social. Es, por otra parte, una escritura que no depende de la oralidad. Lacan se refiere a una escritura 
que no es fonética, que no copia la realidad, y que es efecto del lenguaje. No tiene relación con la memoria, ya que es pura inscripción.

\section{Referencias bibliográficas}

Assoun, P. L. (1994). Introducción a la Metapsicología freudiana. Buenos Aires: Paidós.

Baños Orellana, J. (1995). El idioma de los lacanianos. Buenos Aires: Atuel.

Beliveau, O. (2005). La narrativa en la obra de Freud (tesis inédita para optar por el título de Maestría en Análisis del Discurso). Facultad de Filosofía y Letras, Universidad de Buenos Aires.

Brooks, P. (1992). Reading for the plot. Design and intention in narrative. Cambridge: Harvard University Press.

Calvet, L. (2008). Historia de la escritura: de Mesopotamia hasta nuestros días. Buenos Aires: Paidós.

De Certeau, M. (2007). Historia y psicoanálisis. México: Universidad Iberoamericana, Instituto Tecnológico y de Estudios Superiores de Occidente.

Derrida, J. (1989). Freud y la escena de la escritura. En Jose M. Ortega (Ed.), La escritura y la diferencia (pp. 271-317). Barcelona, España: Anthropos.

Escars, C. (2003). Ensayismo y psicoanálisis. En C. Escars (Ed.), Clínica de la transmisión. Escrituras y lecturas en psicoanálisis (pp. 33-46). Buenos Aires, Argentina: Imago Mundi.

Fages, J. B. (2001). Para comprender a Lacan. Buenos Aires: Amorrortu.

Fasolino, R. (2012). La función de la escritura en Lacan. Escritura e imagen, 8, 277-299.

Février, J. (1948). Histoire de l'écriture. París: Payot.

Freud, S. (1992). Notas sobre la "pizarra mágica”. Obras completas, Tomo XIX (pp. 239247). Buenos Aires: Amorrortu.

Frucella, M. L. (2015). La cuestión de la letra y la controversia Lacan-Derrida. Cortocircuito entre filosofía y psicoanálisis (tesis inédita para optar por el Doctorado en Humanidades). Universitat Pompeu Fabra, Barcelona. 
Fuentes, A. (2010). La función de la escritura en la experiencia psicoanalítica. Letras. Actualidad del pase, 1, 23-27.

Gelb, I. (1985). Historia de la escritura. Madrid: Alianza Editorial.

Haddad, I. (2014). La especificidad del concepto de rasgo unario a la altura del Seminario IX, La Identificación (1961-1962) de J. Lacan: Articulación y distinción entre el rasgo unario, el significante, la letra y el nombre propio. Anuario de investigaciones, 21(2), 63-70.

Kuri, C. (1997). Ensayo de las razones (La desbiografía psicoanalítica). En Ritvo y Kuri (Eds.), Ensayo de las Razones. Acto y Argumentación en Psicoanálisis (pp. 243273). Buenos Aires, Argentina: Letra Viva.

Lacan, J. (2006). Seminario XXIII. El sinthome. Buenos Aires: Paidós.

Lacan, J. (2008). Seminario XX. Aún. Buenos Aires: Paidós.

Lacan, J. (2014). Seminario XVIII. De un discurso que no fuera del semblante. Buenos Aires: Paidós.

Lacan, J. (s. f. a). Seminario IX. La identificación. Inédito. Recuperado de https://www.lacanterafreudianacom.ar/lacanterafreudianajaqueslacanseminario9. html

Lacan, J. (s. f. b). Seminario XIII. El objeto del psicoanálisis. Inédito. Recuperado de http://www.psicoanalisis.org/lacan/seminario13.html

Lacan, J. (s. f. c). Seminario XIV. La lógica del fantasma. Inédito. Recuperado de https://www.lacanterafreudiana.com.ar/lacanterafreudianajaqueslacanseminario1 4.html

Lacan, J. (s. f. d). Recuperado de Lituraterre. https://www.lacanterafreudiana.com.ar/2.1.7.7a\%20anexo\%20LITURATERRE $\% 20 \% 20$ S18.pdf

Lacan, J. (s. f. e). Seminario XXI. Los no incautos yerran o los nombres del padre. Recuperado de http://www.psicoanalisis.org/lacan/seminario21.html

Lacan, J. (s. f. f.). Seminario XXV. El momento de concluir. Recuperado de http://www.psicoanalisis.org/lacan/seminario25.html 
López, H. (2009). La instancia de Lacan: actualidad de la instancia de la letra en el inconsciente o la razón desde Freud. Tomo I y Tomo II. Mar del Plata: Eudem.

Ong, W. (2006). Oralidad y escritura. Tecnologías de la palabra. Buenos Aires: Fondo de Cultura Económica.

Paladino, N. (2003). "El caso Richard o la técnica como caso”. En Escars (Ed.), Clínica de la transmisión. Escrituras y lecturas en psicoanálisis (pp. 81-98). Buenos Aires, Argentina: Imago Mundi.

Platón. (2007). Fedro. Buenos Aires: Losada.

Porge, E. (2007). Transmitir la clínica psicoanalítica. Freud, Lacan, hoy. Buenos Aires: Editorial Nueva Visión.

Saussure, F. (2007). Curso de lingüística general. Tomo I. Buenos Aires: Losada.

Savio, K. (2015). Aportes de Lacan a una teoría del discurso. Folios, 41, 43-54.

Savio, K. (2017). El sujeto de la enunciación: diálogos entre la lingüística y el psicoanálisis. Linguagem em (dis)curso, 17(2), 271-284.

Williams, R. (Ed.). (1992). Tecnologías de la comunicación e instituciones sociales. En Historia de la comunicación (vol. 2). De la imprenta a nuestros días (pp. 181209). Barcelona, España: Bosch.

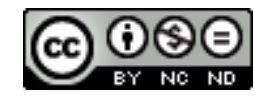

Esta obra está bajo una licencia de Creative Commons Reconocimiento-NoComercialSinObraDerivada 4.0 Internacional 